\title{
DIFFICULTY OF OBTAINING REPRODUCIBILITY IN THE FRANKLIN AND DUKES TEST FOR THE DETECTION OF SPERM-AGGLUTINATING ANTIBODIES IN HUMAN SERA
}

\author{
L. METTLER AND T. GRADL \\ Department of Obstetrics and Gynecology, University of Kiel, \\ D-2300 Kiel 1, Hegewischstrasse 4, West Germany \\ (Received 24th September 1974)
}

\begin{abstract}
Summary. The Franklin and Dukes (FD) test is used as a screening test for the determination of sperm-agglutinating antibodies and as a proof of therapeutic effects in cases of infertility, but various parameters of the FD test remain unclear and the application of different techniques has revealed highly different results. To test the statistical evidence for the FD technique, conditions regarded as optimal prerequisites were applied: a sperm concentration of $20 \times 10^{6} / \mathrm{ml}$ was produced with Baker's buffer and serum dilutions were made with Baker's buffer, starting at $1: 4$. Only the standard deviation of parallel tests with one serum sample and one semen sample on the same day was found to be within an acceptable range. Using ejaculates of the same donor and the same serum sample on different days gave results that were not reproducible. The FD test should not, therefore, be used for quantification of sperm-agglutinating antibodies except for a comparison in one test with one semen sample on the same day. Although the FD test only allowed a qualitative evaluation of sperm-agglutinating antibodies the \% sperm agglutination was more informative than agglutination titres. For quantification of spermagglutinating antibodies, the FD test should be replaced by other techniques.
\end{abstract}

\section{INTRODUCTION}

The phenomenon of sperm agglutination in the sera of women with unexplained causes of infertility was regarded as depending upon the action of an agglutinin before Franklin and Dukes (FD) published their method (Dukes \& Franklin, 1968). Although the sperm-agglutination technique has been considered a poor test for the quantification of agglutinating sperm antibodies (Shulmann, 1971a), it has been widely used. Considerable differences between the results of screening tests concerning the percentage of women with sperm antibodies have been published by different authors: in an unselected population, figures from $7 \%$ to $80 \%$ have been described (Dukes \& Franklin, 1968; Isojima et al., 1972; Schwimmer et al., 1967). 
The reason for spontaneous sperm agglutination often remained unexplained (Boettcher \& Kay, 1969), and the need to use motile spermatozoa in the FD test has been subject to speculation (Shulmann, 1971a). Shulman (1971a) had success with immotile spermatozoa in a capillary test. Many authors question the existence of a correlation between a positive FD test and infertility (Schwimmer et al., 1967). Shulman (1971b) obtained a poor correlation of the results of the FD test with the Kibrick test (Kibrick et al., 1952). The reason may be that the FD test gives good results in sera with head-to-head agglutinations which are not found by the Kibrick test (Friberg, 1974) which predominantly reveals head-to-tail agglutinations.

The poor agreement of the results reported in the literature is caused by modifications of the techniques applied. Some authors use undiluted sera, which do not give good results (Shulman, 1971a). A dilution of $1: 8$ or 1:4 should always be used. In less dilute sera, the prozone phenomenon (Rümke \& Hellinga, 1959) may take place. The ejaculate is mostly diluted with Baker's buffer to $50 \times 10^{6}$ to $20 \times 10^{6}$ spermatozoa/ml. Differences concerning the sperm donors have to be observed. Dukes \& Franklin (1968) used sperm samples from the husband and at least three sperm samples from other donors. Others used pooled semen from a number of donors. One donor of good quality semen for all the studies in one laboratory (Friberg, 1974) has proved to give the best results. Although spontaneous sperm agglutination occurs, an arbitrary lower limit for positive reactions is usually set. Many authors use $10 \%$ agglutination as this limit. Some stir the incubation mixture before putting a drop on the slide, others take a drop from the bottom of the tube. Some authors regard the agglutination of more than ten spermatozoa as positive if more than five of these aggregates can be seen in one sample. We counted as positive only sperm agglutinations of two to ten spermatozoa. The incubation time varies from 30 min to $4 \mathrm{hr}$ at $37^{\circ} \mathrm{C}$.

It was the aim of this study to elucidate the statistical significance and the reproducibility of the FD test and to give it its qualitative or quantitative meaning.

\section{MATERIALS AND METHODS}

Sera of three women with infertility of unknown causes were used. The serum samples (about $1.5 \mathrm{ml}$ ) had been stored at $-20^{\circ} \mathrm{C}$ for not more than 2 months. After thawing, the samples were either used immediately, or stored at $+4^{\circ} \mathrm{C}$ for 2 to 3 days before testing.

Semen samples were obtained from six healthy donors, 24 to 27 years old, by masturbation after a minimum of 3 days continence. The original sperm counts varied from $80 \times 10^{6}$ to $120 \times 10^{6} / \mathrm{ml}$. A minimal motility of $60 \%$ was required. Semen containing leucocytes or cell detritus was discarded. The samples used contained only a few morphologically abnormal spermatozoa.

The sperm count was adjusted with Baker's buffer $(30 \mathrm{~g}$ glucose; $1.7 \mathrm{~g}$ $\mathrm{Na}_{2} \mathrm{HPO}_{4} .2 \mathrm{H}_{2} \mathrm{O} ; 2 \mathrm{~g} \mathrm{NaCl} ; 0.1 \mathrm{~g} \mathrm{KH}_{2} \mathrm{PO}_{4}$ in 1 litre distilled water) to a final concentration of $20 \times 10^{6}$ spermatozoa $/ \mathrm{ml}$. The serum was diluted with Baker's buffer and $200 \mu \mathrm{l}$ of the diluted serum were mixed with $20 \mu \mathrm{l}$ of the diluted 
semen in a narrow tube. If insufficient serum was available, samples of $100 \mu \mathrm{l}$ diluted serum with $10 \mu \mathrm{l}$ diluted semen were used. After sealing and shaking, the samples were incubated for $90 \mathrm{~min}$ at $37^{\circ} \mathrm{C}$. The tubes were then agitated and one drop of the mixture was placed on a microscope slide. A total of 100 cells was counted and characterized as (1) motile, (2) showing tail movements only and (3) immotile spermatozoa. Within about $10 \mathrm{sec}$, one microscope field was examined. For Grades 1 and 2 the agglutination numbers as well as the number of spermatozoa forming these clumps were counted separately. Only head-to-head agglutinations could be observed in the three sera examined. Abnormal forms of spermatozoa were evaluated if they were motile, but agglutinated abnormal forms were discarded. Two observers made all the assessments in this study. A warm-stage microscope was not available. The test was concluded when the sperm motility dropped below 30\%. The time from ejaculation to completion of the sperm count was between 5 and $8 \mathrm{hr}$. From 3 to $6 \mathrm{hr}$ were needed for the counting procedure.

Nine tests in five parallels with dilutions from 1:2 to $1: 32$ were performed. One serum was tested five times and two sera were tested twice. Thus, a total of 263 tests were performed.

For each dilution step the mean agglutination value and standard deviation from the five parallels was computed. Agglutinated spermatozoa of Grades 1 and 2 revealed the percentage of agglutinations.

\section{RESULTS}

\section{Standard deviation of the Franklin and Dukes test}

The methodological standard deviation (S.D.) of the FD test under identical conditions (same day, same serum sample, one dilution step, same semen sample) ranged from \pm 1.9 to $\pm 8.4 \%$ agglutinations. These values depend upon the quality of the semen sample. In all tests with the same semen sample, the S.D. of the different dilution steps were closely related. Thus, a mean S.D. for each sperm donor on one particular day was computed. This value differed considerably on different days for the same sperm donor $(26 \%$ to $62 \%$ ). Different sperm donors had an even wider range of S.D. (from $11.8 \%$ to $63 \%$ ). There were considerable differences in sperm quality in the parallel tests. The percentage of Grade 2 and Grade 3 spermatozoa showed wide variations, those for Grade 2 fluctuating from 3 to $25 \%$ and those for Grade 3 from 24 to $53 \%$. Although the mean values remained the same for $8 \mathrm{hr}$, the range of fluctuations increased about one-third during this time. This may have been due partly to fluctuations in temperature.

The sperm-agglutination activity of the applied sera with the semen of the same donor on different days showed wide variation. Comparison at 1:4 dilutions demonstrated differences from $26 \cdot 0 \pm 2 \cdot 6$ to $62 \cdot 0 \pm 6 \cdot 1 \%$ of agglutinations (Table 1). Tests of semen from different donors revealed a similar range of agglutination activities $(11.8 \pm 1.9$ to $63.4 \pm 7.3 \%)$.

A comparison of the results of tests on different days was, therefore, impossible. Neither a reduction nor an augmentation of agglutination activity could be detected. 
Table 1. Sperm-agglutination activity of sera from three women tested against semen from six donors

\begin{tabular}{|c|c|c|c|c|}
\hline \multirow{2}{*}{ Donor } & \multirow{2}{*}{ Date } & \multicolumn{3}{|c|}{ Mean sperm-agglutination activity $(\% \pm S . D)}$. \\
\hline & & Serum I & Serum $I I$ & Serum III \\
\hline A & $13 / 5 / 74$ & $26 \pm 2 \cdot 6$ & - & - \\
\hline $\mathrm{A}$ & $26 / 6 / 74$ & $62+6 \cdot 1$ & - & - \\
\hline A & $28 / 6 / 74$ & - & $12 \cdot 2 \pm 2 \cdot 6$ & - \\
\hline B & $22 / 5 / 74$ & $63 \cdot 4 \pm 7 \cdot 3$ & - & - \\
\hline B & $9 / 7 / 74$ & - & - & $10 \cdot 8 \pm 1 \cdot 1$ \\
\hline C & $12 / 6 / 74$ & $24 \cdot 0 \pm 3 \cdot 4$ & - & 二 \\
\hline D & $2 / 7 / 74$ & - & $16 \cdot 4 \pm 3 \cdot 3$ & - \\
\hline $\mathbf{E}$ & $4 / 7 / 74$ & $11 \cdot 8 \pm 1 \cdot 9$ & - & - \\
\hline $\mathbf{F}$ & $8 / 7 / 74$ & - & - & $2 \cdot 8 \pm 2 \cdot 0$ \\
\hline
\end{tabular}

The $\%$ sperm-agglutinating activity was computed from five parallel tests applying the Franklin and Dukes test at $1: 4$ dilutions of sera.

\section{Application of titres in the FD test}

The dose-response curves for all tests were plotted in log-normal diagrams. Starting at dilutions of $1: 4$, a linear relationship resulted which was seldom well adjusted (Text-fig. 1).

To test the evidence for \% agglutination activity, the regression and its S.D. (95\% confidence level) were computed for two of the titration curves. Both variances, in $x$ (log of dilutions) and $y$ (agglutination activities) were large. The variance for $y$, however, was a little smaller for both curves. Because of the coarse graduation of the abscissa (dilution steps of only $1: 4$ to $1: 32$ ), titres proved to be less informative (the variance ranges within three or all four of the applied geometrical titre steps) than agglutination activities. The arbitrary assumption of a lower limit for positive results ( $10 \%$ agglutinations in our laboratory) is a further reason for preferring to measure sperm-agglutination activity as a percentage.

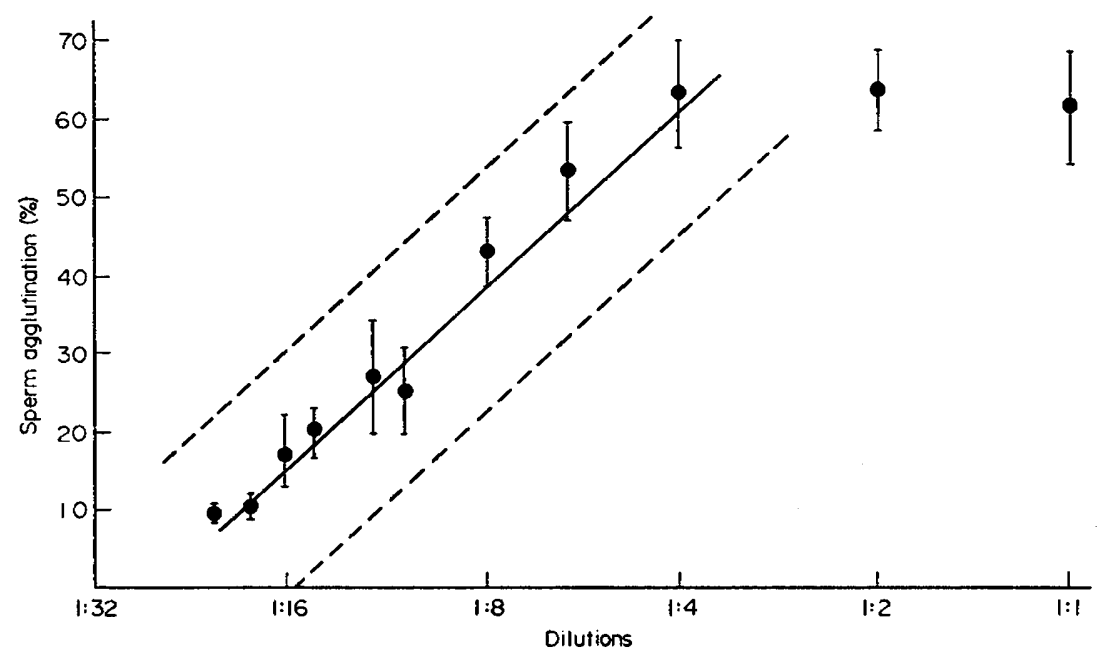

TEXT-FIG. 1. Titration curve of sperm-agglutinating serum. The regression is computed from five parallel dilution series $1: 4$ to $1: 25$. The S.D. at the $95 \%$ confidence level are represented by the vertical bars. 


\section{DISCUSSION}

The FD test is useful for revealing the presence of sperm-agglutinating antibodies in sera (Mettler et al., 1974). It can be applied to distinguish fertile patients and those infertile due to mechanical or endocrinological failure, and those who are sensitized to spermatozoa, since the incidence of FD positive cases is significantly higher in a population of unexplained infertility in comparison to other groups. Because of its poor reproducibility, however, the FD test can only be used qualitatively. A comparison of agglutination values is only justified if the test is performed with one semen sample on one day. In our studies, the FD test proved useless for quantification of sperm-agglutinating antibodies. For any quantitative examination concerning an augmentation or reduction of antibody activity that might be required in the treatment of infertility, other tests should be applied, e.g. the microagglutination technique as developed by Friberg (1974) or quantitative immunoelectrophoresis of purified antibodies (unpublished).

\section{ACKNOWLEDGMENTS}

The investigation was supported by Deutsche Forschungsgemeinschaft SFB 111. We acknowledge the technical assistance of Birgit Meseck-Selchow, Silke Klinck and Eleonore Bertling.

\section{REFERENCES}

BOETTCHeR, B. \& KAY, D. (1969) Fractionation of a human sperm-agglutinating serum. Nature, Lond. 229, 737-738.

Dukes, C.D. \& FrankLin, R.R. (1968) Sperm agglutinins and human infertility; female. Fert. Steril. 19, 263-267.

FriberG, J. (1974) Clinical and immunological studies on sperm-agglutinating antibodies in sera and seminal fluid. Acta obstet. gynec. scand., Suppl. 36, 3-76.

Isojima, S., Tsuchrya, K., Koyama, K., Tanaka, C., NAKa, O. \& Atachi, H. (1972) Further studies on sperm immobilizing antibodies found in sera of unexplained cases of sterility in women. $A m$. 7. Obstet. Gynec. 112, 199-207.

Kibrick, S., Belding, D.L. \& Merrinl, B. (1952) Methods for the detection of antibodies against mammalian spermatozoa Fert. Steril. 3, 430-438.

Mettler, L., Scheidel, P. \& Schirwani, D. (1974) Sperm antibody production in female sterility. Int. F. Fert. 19, 7-12.

Rümke, P. \& Hellnga, G. (1959) Autoantibodies against spermatozoa in sterile men. Am. F. clin. Path. 32, 357-363.

Schwimmer, W.B., Ustay, K.A. \& Behrman, S.J. (1967) An evaluation of immunologic factors of infertility. Fert. Steril. 18, 167-180.

Shulman, S. (1971 a) Sperm antibodies as a cause of infertility. CRC Crit. Rev. clin. lab. Sci. 2, 393-460.

Shulman, S. (1971b) Immunity and infertility: a review. Contraception 4, 135-154. 